\title{
THERMO-HYDRODYNAMIC BEHAVIOR OF METHANOL CHARGED CLOSED LOOP PULSATING HEAT PIPE
}

\author{
Rahul S. Borkar*, Pramod R. Pachghare \\ Department of Mechanical Engineering, Government College of Engineering, Amravati-444 604, India
}

\begin{abstract}
Flow visualization experiment has conducted on the methanol charged vertical Closed Loop Pulsating Heat Pipe (PHP) to investigate the effect of different heat inputs on overall thermal resistance, average evaporator and condenser temperature and corresponding hydrodynamic behavior. A PHP has made from four parallel glass tubes forming adiabatic section, interconnected alternately by copper U tubes, having internal and external diameter $2 \mathrm{~mm}$ and $3.06 \mathrm{~mm}$ respectively. The length of evaporator, condenser and adiabatic section are $42 \mathrm{~mm}$, $50 \mathrm{~mm}$ and $170 \mathrm{~mm}$ respectively. For experimentation, filling ratio (FR) $50 \%$ and vertical bottom heating mode position was maintained. Electrical heat input to the evaporator varies from $8 \mathrm{~W}$ to $80 \mathrm{~W}$ with interval of $8 \mathrm{~W}$ after steady state was reached. The result shows that, thermal resistance of a PHP rapidly decreases with increasing heating power from $8 \mathrm{~W}$ to $32 \mathrm{~W}$ and thereafter reasonably steady for further heating powers. From visualization it is observed that, the thermal performance of a PHP is dependent on the flow patterns in PHP tubes. Continuous unidirectional flow circulation in the tubes of PHP gives best thermal performance than pulsation and dry-out conditions.
\end{abstract}

Keywords: Pulsating, phase, passive, heat, flow pattern

\section{INTRODUCTION}

The Pulsating Heat Pipe (PHP) is a two-phase passive heat transfer device proposed and patented by Akachi (1990). A PHP is simple in structure with a small diameter coil partially filled with certain working fluid in it and extended from the heat source to sink. PHP uses the technique of transporting the working fluid by means of differential pressure across liquid slugs and vapor plugs from evaporator to condenser and reverse. The fluid from the evaporator is pushed towards the condenser in the form of discrete liquid slugs and vapor bubbles. The vapor gets partially condensed at the condenser where it loses its latent heat and then returns to evaporator and completes the cycle. A PHP is being explored for thermal management of electronic devices to remove heat without any electrical power supply and it able to dissipate substantial amount of heat with small temperature drop, simple design and low cost.

Tong et al. (2001) observed that during the startup period the working fluid oscillate with large amplitude, after this period continuous circulation of the working fluid occurs. The direction of circulation for working fluid is consistent once circulation is obtained but the direction of circulation can be different for same experimental run. Smaller vapor bubbles have larger upward flow velocities and slower downward flow velocity.

Khandekar and Groll (2003) conducted experiments on a PHP made of copper capillary tube of $2 \mathrm{~mm}$ inner diameter for three different working fluids viz. water, ethanol and R-123. The PHP was tested in vertical (bottom heat mode) as well as horizontal orientation and indicated that, a 100\% filled PHP (not working in the pulsating mode but instead as a single-phase buoyancy-induced thermosyphon) is thermally better performing than a partially filled pulsating mode device under certain operating conditions. Higher input heat fluxes result in a transition of slug flow to annular flow at the outlet of the evaporator U-bends. Since the evaporator U-sections experience convective boiling through the thin liquid film rather than nucleate type boiling in slug flow regime. Khandekar and Groll (2004) studied that, complete stop-over is in the loop occurs more frequently for filling ratio $<50 \%$ coupled with low heat input power. Stop-over phenomenon has also been observed for higher filling ratios. The 'self-sustained' oscillating character is then lost, such a behavior has never been reported for multi-turn PHPs because of alternating periods in which bubble plugs are moving rapidly (activity phase) and 'stopping' (static phase). Khandekar et al. (2009) observed that the quasi-steady state corresponding to best thermal performance consists of continuous unidirectional flow circulations, while the state corresponding to poor thermal performance is characterized by the intermittent bidirectional flow reversals. Oscillating Taylor bubble flows require immediate attention (Khandekar et al., 2010), unless the nuances of oscillatory confined bubbles in small capillaries is well discerned, the net pressure drop correlations for a PHP cannot be exhaustively constructed.

Dadong and Cui (2010) indicated that the thermal resistance decreases with the increase of the heating power at the same filling ratio. For the pure working fluid PHPs, the thermal resistance is decreases in the sequence of water, ethanol, methanol and acetone. No measurable difference has been recorded between a PHP running with the azeotropic mixture and a PHP running with pure ethanol, in terms of overall thermal resistance Mameli et al. (2011).

Pachghare and Mahalle (2012) conducted experiments on PHP to investigate the effect of binary mixture of working fluids on thermal performance of PHP, made from copper tube with $2 \mathrm{~mm}$ inner diameter and 10 numbers of turn, for different heat inputs with ethanol, methanol, acetone, water and their binary mixture with water as a working fluids at filling ratio $50 \%$. Pure acetone is having lesser thermal resistance than working fluids methanol, ethanol, and water. 
No measurable difference has been recorded between the PHP running with pure and binary mixture working fluids, in terms of overall thermal resistance. Working fluid behavior is strongly depends on the thermo-physical properties, but latent heat of vaporization is the main property that strongly affects the thermal performance.

Narasimha et al. (2012) studied that, at atmospheric condition; the saturation temperature is higher compared to evacuated situation. Thus more liquid phase exists in the tube with a consequent increase in the heat transfer. Kammuang-lue et al. (2008) studied that, the higher latent heat of the working fluid the higher critical heat flux. Yang et al. (2009) pointed out that increasing heat load clearly improves the thermal performance. Meena et al. (2009) concluded that as working fluids change from R123 to Ethanol and water the critical heat flux decreased. The latent heat of vaporization affects the critical heat flux. The working fluid with the lower latent heat of vaporization exhibits a higher critical heat flux. Mass transfer characteristics are also affected by the local hydrodynamic properties of the flow (Bercic and Pintar, 1997).

To study the effect of flow pattern on thermal performance, an experimental set-up designed for pure convection model. Therefore, borosilicate glass tubes are used in the adiabatic section for visualization and heat transfer by pure convection. Various temperatures are recorded on the wall of PHP .Thermal performance is measured in terms of overall thermal resistance for various heat inputs also flow patterns are captured and analyzed with the thermal performance.

\section{EXPERIMENTATION}

\subsection{Experimental set-up}

The experimental set-up of PHP was developed as shown in Figure 1. The details of copper-glass tube assembly and evaporator tank as shown in Figure 2. The set-up consists of a closed loop PHP, temperature recorder, power supply unit, and water tank cooling system for condenser.

A PHP, consisting of 2 turns, the presence of two U-turns and four parallel channels increases the level of perturbations thereby diminishing the probability of phase recoiling and consequent complete stop-over of the fluid motion.

Evaporator sections (Length $42 \mathrm{~mm}$ ) and condenser sections (Length $50 \mathrm{~mm}$ ) are made of copper capillary tube having inner diameter is $2 \mathrm{~mm}$ and the outer diameter is $3.06 \mathrm{~mm}$. The adiabatic section (Length $170 \mathrm{~mm}$ ) made from borosilicate glass tube to understanding flow pattern for different heat inputs. Fluid motion and flow patterns have been captured with a camera (Nikon ${ }^{\circledR}$, COOLPIXP60, 8.1 Megapixel, 5X Zoom) just above the evaporator section.
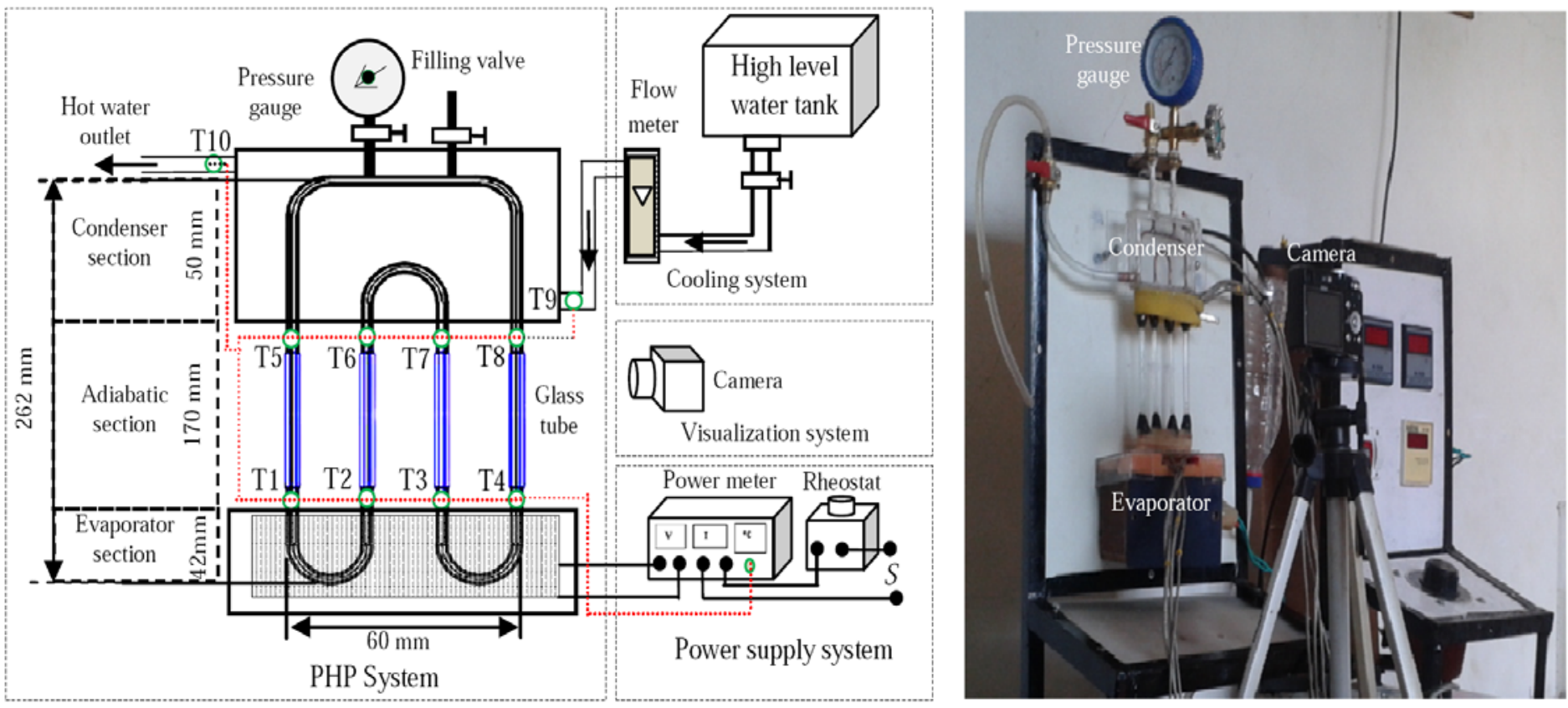

Fig. 1 Schematic and photograph of experimental set-up

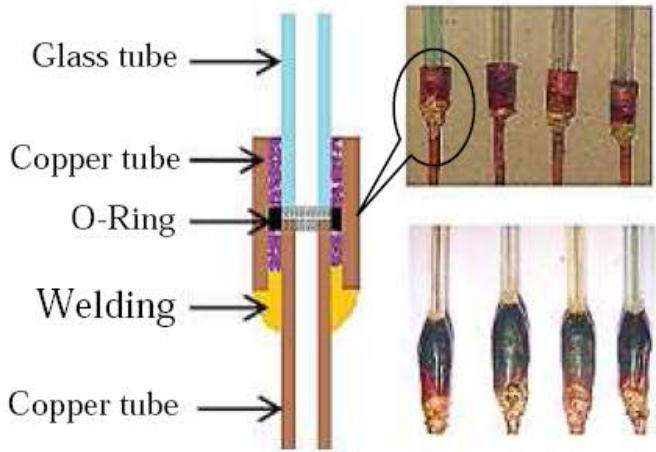

(a)

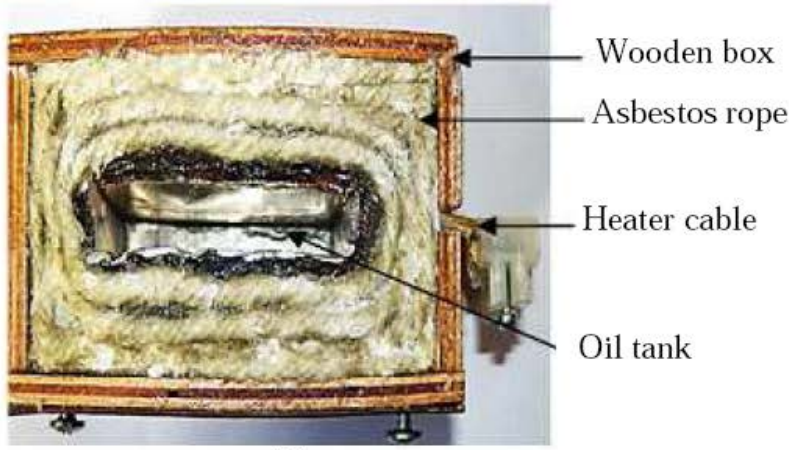

(b)

Fig. 2 Assembly details (a) copper and glass tubes (b) evaporator tank 
The heating power is provided by a carefully designed power supply unit. Heating was done by oil bath and cooling by water tank with maintained $30 \mathrm{ml} / \mathrm{min}$ water flow rate through condenser. The power meter measures the AC voltage, the current and the corresponding temperature simultaneously. The filling ratio $50 \%$ was maintained. The heating configuration was bottom heat orientation. For temperature measurements, ungrounded sheathed thermocouples (KType, accuracy $\pm 0.2^{\circ} \mathrm{C}$ and $\mathrm{D}=0.5 \mathrm{~mm}$ ) were used. All the thermocouples are mounted on the wall of the PHP tubes.

Filing of the PHP is only done when the internal vacuum level is at least lower or equal to 0.99 bar. Relation of surface tension and bouncy could be explained by the dimensionless formula in Eq. (1):

$$
\mathrm{E} \ddot{\mathrm{O}}=\frac{\mathrm{gD}_{\text {cri }}^{2}\left[\rho_{\text {liq }}-\rho_{\mathrm{vap}}\right]}{\sigma}
$$

When Eö $=4$, the bubble will get seized on both size of wall. At this condition, the terminal velocity becomes zero and the fluid slug flow is formed. The inner diameter of the tube must be small enough such that liquid vapor plugs and slugs exist. Such condition is ensured only if inner diameter of a tube is smaller than a critical diameter. The required diameter calculated by using following Eq. (2).

$$
D_{c r i} \leq 2 \times \sqrt{\frac{\sigma}{g\left[\rho_{\text {liq }}-\rho_{\text {vap }}\right]}}
$$

All tubes have inner diameter $(2 \mathrm{~mm}$ ) less than critical diameter. Two smaller copper tubes has been brazed on the main tube of the condenser section in order to connect the vacuum/filling valve and pressure indicator as shown in Figure 1.

The glass tube attached to copper tubes in the condenser section and evaporator section by following procedure:

1. At each end of the U-turns a $5 \mathrm{~mm}$ inner diameter copper tubes are attached by welding (i.e. copper fitting).

2. The $4 \mathrm{~mm}$ inner diameter of glass tubes are inserted in the copper fitting and coupled to the copper tubes by mean of an O-ring.

3. Mixture of m-seal and araldite is fill in the remaining gap between the copper fitting and the glass tube above and below the O-ring, thus ensuring a good seal as shown in Figure 2-a.

The evaporator section was heated by oil bath for uniform heating. A flat flexible heater ( $450 \mathrm{~W}$ ) has been placed at one side of the evaporator oil tank. Insulation is provided on tank by two asbestos sheet (width: $3 \mathrm{~mm}$ ) and the whole assembly is kept in wooden block, remaining gaff between oil tank and wooden block wall is filled with glass wool for better insulation and asbestos rope is kept on glass wool and fixed by araldite as shown in Figure 2-b.

\subsection{Experimental procedure}

The experimental set-up is used for experimentation and the following procedure is adopted during the present transient experiment:

1. Before filling the working fluid, it is ensured that there is no other fluid exists inside the tubes of PHP.

2. In order to obtain vacuum inside the PHP, a reciprocating vacuum pump is connected to the filling valve. Filing of the PHP is only done when the internal vacuum level is lower than or equals to 0.99 bar.

3. Once the evacuation of the PHP system is complete, the valves are closed. The required amount of working fluid is then filled by opening the one valve as shown in Figure 1. The PHP is filled with the working fluid with a filling ratio $50 \%$ at ambient temperature $\left(25^{\circ} \mathrm{C} \pm 2{ }^{\circ} \mathrm{C}\right)$.

4. The cooling water is allowed to the condenser section of PHP from the constant water bath and the amount of cooling water $30 \mathrm{ml} / \mathrm{min}$ is maintained during entire experimentation.
5. The temperature indicator is then switched on to record the temperature.

6. The required input heat power supply from control panel.

7. Transient experiments are conducted with different heating input.

8. After a quasi-steady state was reached continuous movies were recorded and photographs were taken at specified times by digital camera. At steady state from inlet, outlet temperature and mass flow rate of coolant the heat transfer rate through PHP calculated.

9. Evaporator and condenser temperature recorded at each steady state and again increase heating power by $8 \mathrm{~W}$. Repeat this step until 80W.

\section{RESULTS AND DICUSSIONS}

Experimentation conducted on the methanol charged PHP at vertical bottom heat mode. Heat input to the evaporator section has been increased with steps of $8 \mathrm{~W}$, starting from $8 \mathrm{~W}$ to $80 \mathrm{~W}$. When, the steady-state was reached for each heat input level then temperature for different points recorded and the overall thermal performance of the PHP has been estimated.

In the ideal measurement, the value assigned by the measurement would be the actual value of the physical variable intended to be measured. However, measurement errors bring on an uncertainty in the correctness of the value resulting from the measurement. To give some measure of confidence to the measured value, measurement errors must be identified, and their probable effect on the result estimated. Uncertainty is simply an estimate of a possible value for the error in the reported results of a measurement. There are four thermocouples mounted in the evaporator section and four in the condenser section and hence the uncertainty in the evaporator temperature and condenser temperature are evaluated about 5\% (Kline et al., 1953).

The overall thermal resistance of PHP defined as the ratio of the average temperature difference between the evaporator and condenser to the power input. It can be calculated as:

$$
\mathrm{R}_{\mathrm{th}}=\frac{\mathrm{T}_{\mathrm{e}}-\mathrm{T}_{\mathrm{c}}}{\mathrm{Q}}
$$

Where, Q is heat input power to the PHP at evaporator by considering thermal loses.

\subsection{Heat transfer capability}

Figure 3 shows that the variation of thermal resistance at different heat inputs for methanol charged PHP. From Figure 3, it is clear that, the thermal resistance decreases with increase in heat input up to 40W. The thermal resistance is dependent on the temperature difference and applied power; as the input heat power increases the temperature difference between evaporator and condenser decreases.

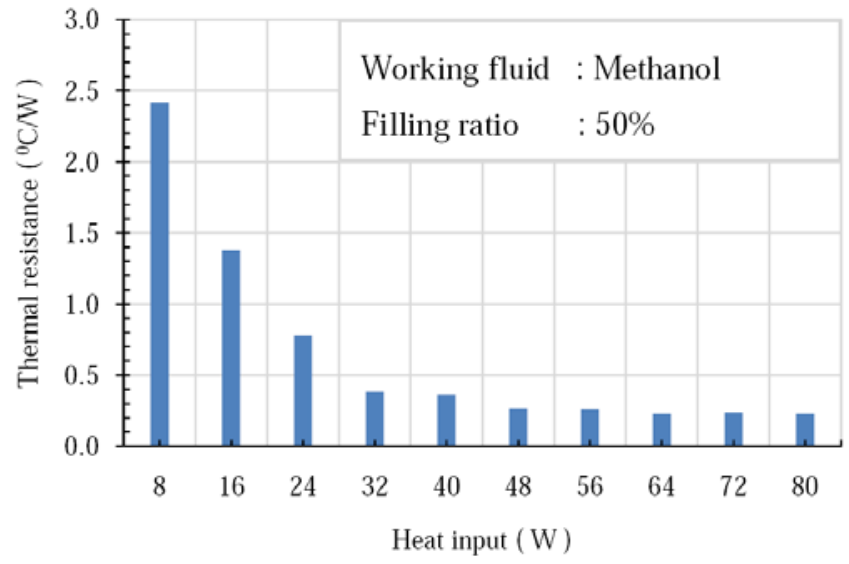

Fig. 3 Thermal resistance of methanol PHP for different heat inputs 
With increasing heat input, the evaporator temperature rises resulting in a greater density gradient in the tubes. Simultaneously the liquid viscosity also drops diminishing the wall friction and evaporation of working fluid inside the tube of PHP. Methanol PHP most suitable for heat input 40 to $80 \mathrm{~W}$ gives uniform performance.

\subsection{Formation of slug-plug pattern}

When working fluid filled in to the evacuated tube of PHP, the working fluid randomly distributed inside the tubes in the form of liquid slugs and vapor plugs train automatically. The coexistence of liquid slugs and vapor plugs of different lengths in their initial condition as shown in Figure 4-a. Due to the evacuation, the boiling temperature of working fluid fall down and partial evaporation occur. The tube is partially filled (50\%) and has capillary dimension, surface tension force dominate over the gravitational force and train of liquid slugs and vapor plugs having menisci on their edges is formed, as shown in Figure 4-b. The amount of liquid phase in the PHP depends on filling ratio. Higher filling ratio implies that there is more liquid phase than vapor phase.

\subsection{Startup behavior of PHP}

Slug fluctuation in PHP (stage-1 ${ }^{\text {st }}$ ): When heating start (8W) at evaporator section, the temperature of evaporator section increased but very small changes observed at temperature of condenser section. Heating power $8 \mathrm{~W}$ is insufficient to start proper evaporation there for very less amount of heat transfer towards the condenser section from evaporator section by local axial fluctuation and phase changes in working fluid as shown in Figure 5. Further when heating power increased from $8 \mathrm{~W}$ to $16 \mathrm{~W}$ rate of fluctuation increased with rising the condenser temperature because of transmission of heat towards the condenser. The basic phenomenon behind fluctuation is nucleate boiling occur at liquid slugs, thus size of adjacent vapor plug increased consequently, at same time because of heating vapor plug expand cause pressure rise in evaporator section. This vapor plugs pushes the liquid column toward the low temperature condenser section. The temperature and pressure decrease in the condenser section because of to condensation. Therefore, constant unsteady internal pressure difference exists in the tube of PHP which is the driving force.

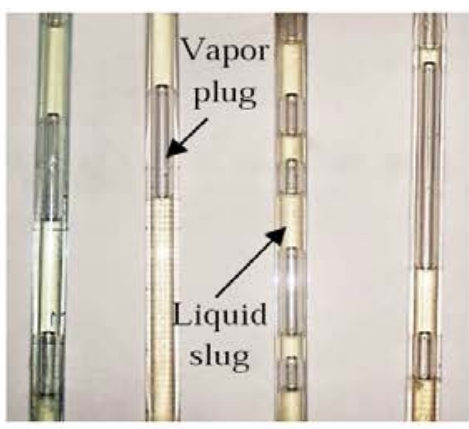

(a)
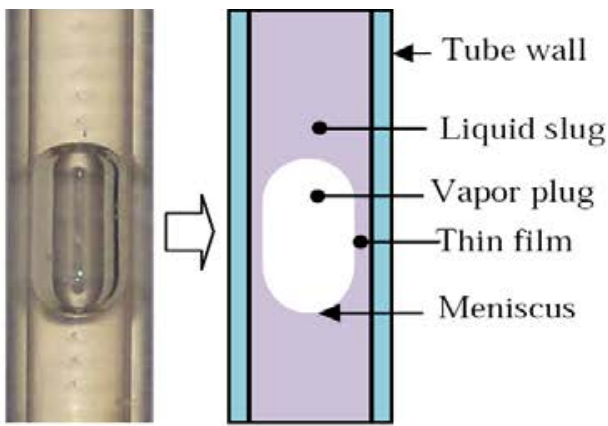

(b)

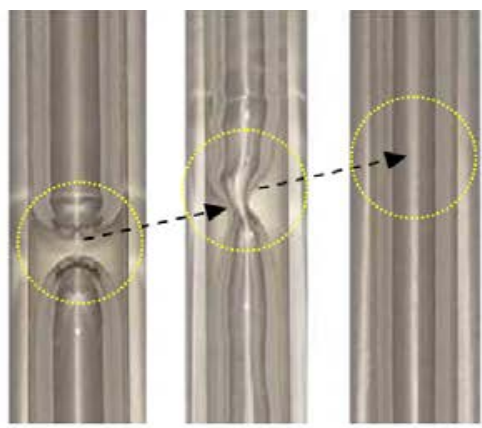

(c)

Fig. 4 Flow visualization (a) flow pattern after filling (b) plug and slug profile (c) transmission from slug to annular pattern

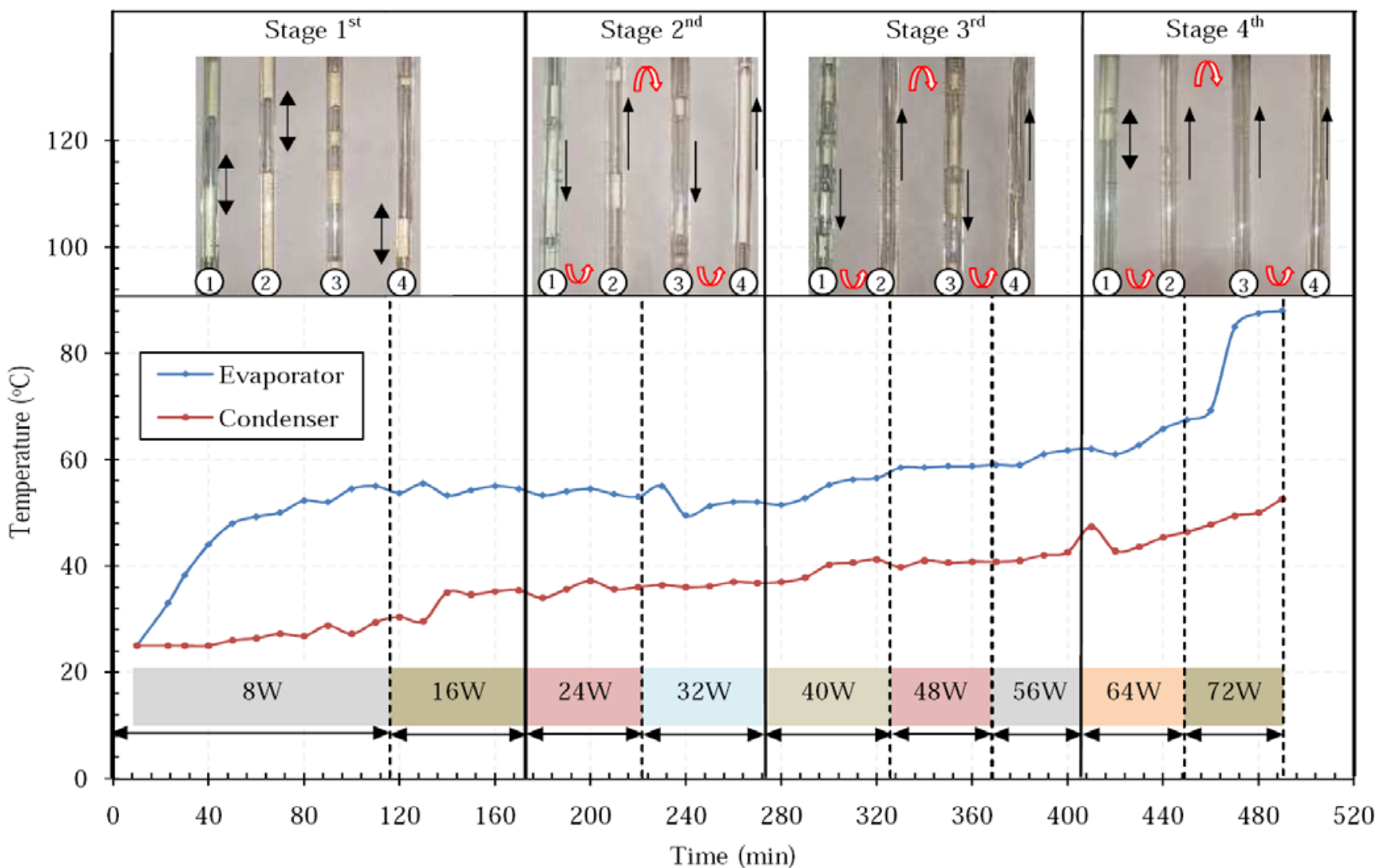

Fig. 5 Evaporator, condenser temperature and corresponding flow pattern at different heat inputs 
The tubes are interconnected; therefore motion of liquid slugs and vapor plugs at one section of the tube toward the condenser also leads to the motion of slugs and plugs in the next section toward evaporator section this works as the restoring force. The inter-play between the driving force and the restoring force leads to pulsation of the vapor plugs and liquid slugs in the axial direction.

One directional circulation in PHP (Stage-2 ${ }^{\text {nd }}$ ): Again when heating power increase $(24 \mathrm{~W})$, within a short interval of time one directional oscillatory semi-annular circulation observed, this happened because pressure at a point " $A$ " is higher than " $B$ " then flow can be initiate as shown in Figure 6. One directional circulation starts automatically without any mechanical moving component in the system.

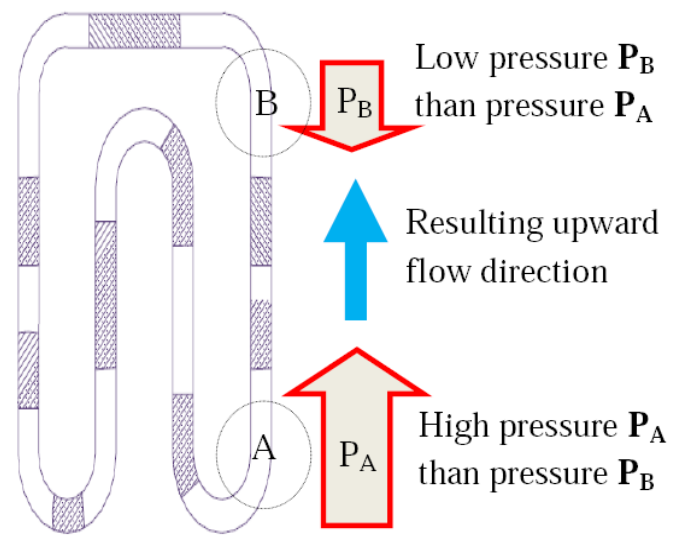

Fig. 6 Flow circulation startup

Flow pattern change from oscillation flow to oscillatory one directional circulation flow and thermal resistance decrease, it means, in case of oscillatory one directional circulation more heat transfer than only oscillation flow with evaporator and condenser temperature profile same as $16 \mathrm{~W}$. The term “oscillatory circulation” used because, during circulation liquid sludge oscillates axially. One directional circulation occurs because of following phenomenon.

If two-phase fluid come from condenser to evaporator in $1^{\text {st }}$ tube convection and nucleate boiling occur in vapor plug and liquid slug respectively resulting size and pressure increase in vapor plug at evaporator section cause push the surrounding liquid slug in $2^{\text {nd }}$ tube towards condenser section. Due to the symmetry the same phenomena are also happening in $3^{\text {rd }} \& 4^{\text {th }}$ tube respectively as shown in Figure $5 \& 7$, during the circulation thin liquid film surrounding vapor plug is always available. The quantity of vapor in $2^{\text {nd }} \& 4^{\text {th }}$ tube is higher than $1^{\text {st }}$ and $3^{\text {rd }}$ tube because of evaporation and condensation respectively. $1^{\text {st }} \& 3^{\text {rd }}$ tube supply liquid slug with uncondensed vapor plug to evaporator for absorb heat and $2^{\text {nd }} \& 4^{\text {th }}$ tube supply evaporated vapor to condenser for loss heat, cycle of the evaporation and condensation is continuous in entire operation.

At heating power $32 \mathrm{~W}$ oscillatory circulation flow convert in to uniform circulation flow, evaporator temperature slightly increased but no effect on condenser temperature observed. Thermal performance is better than heating power $24 \mathrm{~W}$; hence heat transfer capability is more in case of uniform circulation than oscillatory one directional circulation. Similar results also recorded by Khandekar et al. (2009).

Flow pattern transition (Stage-3 ${ }^{\text {rd }}$ ): When further heating load increased (40W) the evaporation rate increases, slug coming from condenser evaporate completely when reached to evaporator, because of high heat power. The vapor pressure in the evaporator section is now able to break most of the liquid slug menisci bridges (see Figure 4-c) and therefore up-comer flow pattern changing from semi-annular to pure annular known as "flow pattern transition". The liquid film is thick and wavy. The above flow pattern observed for input powers $40 \mathrm{~W}$ to
56W with decreasing quantity of down comer liquid slug and slightly increasing evaporator and condenser temperature with respect to input heat power.

Figure 7 illustrates that the flow directions during the operation of methanol PHP at different input heat power. During one directional circulation the neighboring capillary tube always have an inverse direction. When PHP is trying to switch from one flow direction (anti clockwise) to another direction (clockwise) then flow direction in all capillary tubes was changed. The flow direction switch process observed at 40 and 56W input heat power.

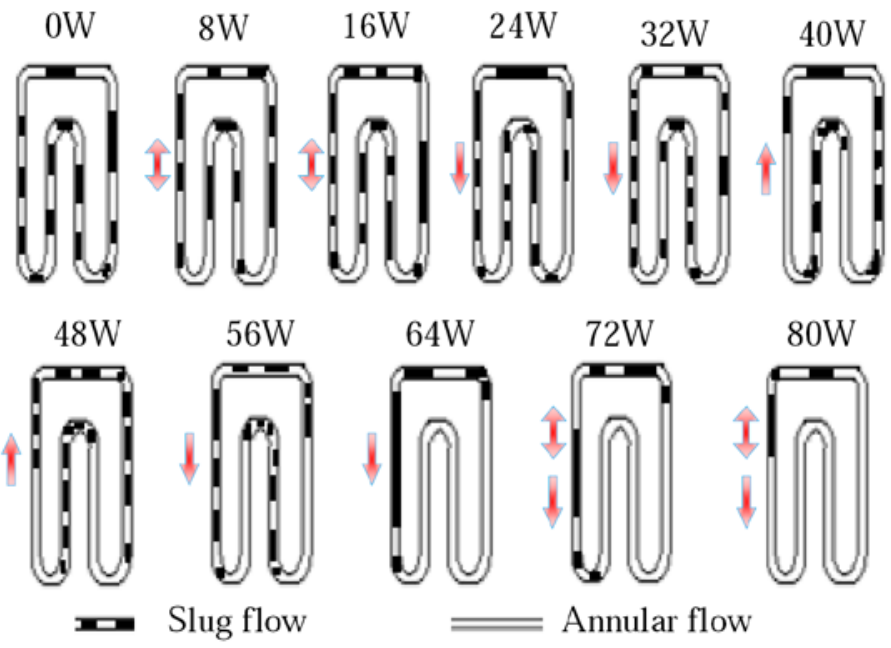

Fig. 7 Flow pattern, flow direction and switch phenomenon for different heat input at steady state

Before dry out condition (Stage- $4^{\text {th }}$ ): Again when heat load increased, in these cases, the rate of evaporation is much higher than condensation there for the condenser unable to condense superheated vapor from evaporator. Slug fluctuate only in $1^{\text {st }}$ tube and pure annular flow observed in $2^{\text {nd }}, 3^{\text {rd }}$ and $4^{\text {th }}$ tubes (see Figure 5) with very thin liquid film on the inner surface of tube because of shortage of working fluid in liquid form at evaporator section, therefore evaporator temperature increase rapidly, resulting, evaporator-condenser temperature difference increases therefore increases in thermal resistance, this condition was observed at heat input $64 \mathrm{~W}, 72 \mathrm{~W}$ and $80 \mathrm{~W}$ as shown in Figure 7 schematically. Shortage of liquid slug increase with increasing heat input because of higher rate of evaporation and insufficient condensation.

\subsection{Flow pattern characterization}

From the visualization of methanol PHP, it is recorded that different type of bubbles formed during the operation are characterized as fallows.

Dispersed bubbles are spherical shape and have less diameter than the inside diameter of the capillary tube. The dispersed bubbles are created by the continuous nucleated boiling, if the coalescence does not occur in the evaporator section. The dispersed bubbles are so small that they are quickly condensed and form slugs once they are out of the evaporator, that span almost the entire cross section of channel, resulting flow regime referred as slug flow as shown in Figure 8.

Vapor plugs are the bubbles in cylindrical form have length higher than the diameter of tube. A part of an expanding dispersed bubble breaks away from it and travels further to merge with another bubble encountered in the way form vapor plug as shown in Figure 9. Motion and shape of the vapor plugs depend on the exerted pressure on both sides of plugs, if pressure at upward direction $\left(\mathrm{P}_{2}\right)$ is higher than downward $\left(\mathrm{P}_{1}\right)$ then the plug moves upward direction and during motion the shape of vapor plug as shown in Figure 10. 

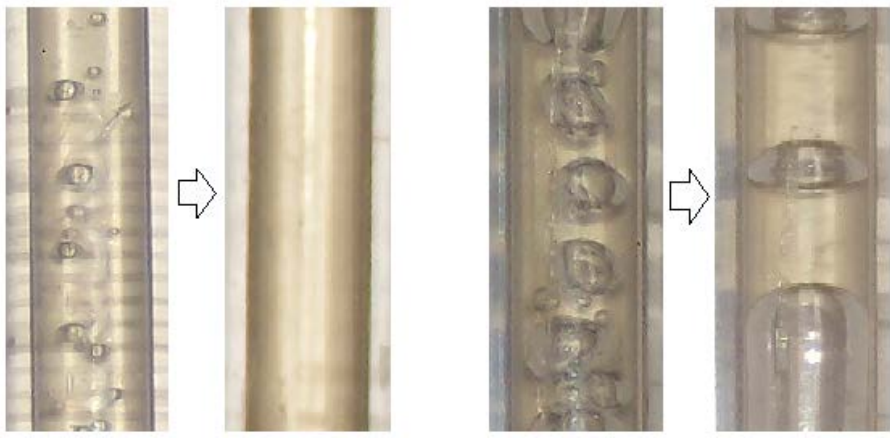

Fig. 8 Dispersed bubble
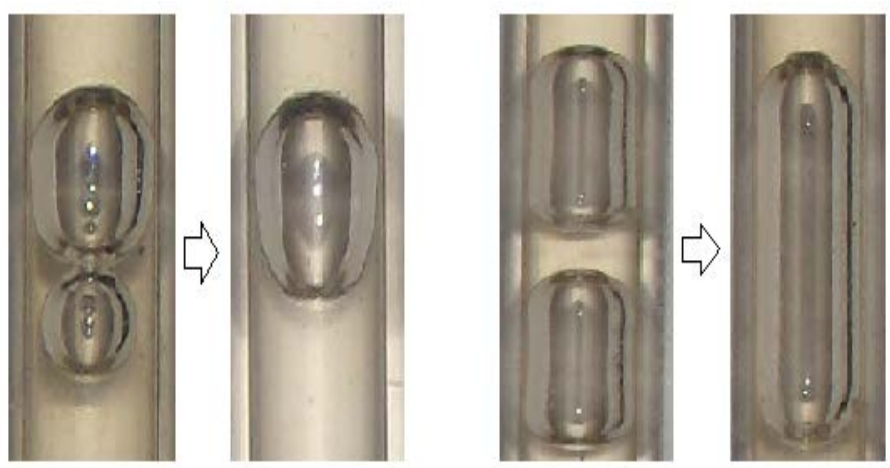

Fig. 9: Vapor plugs.

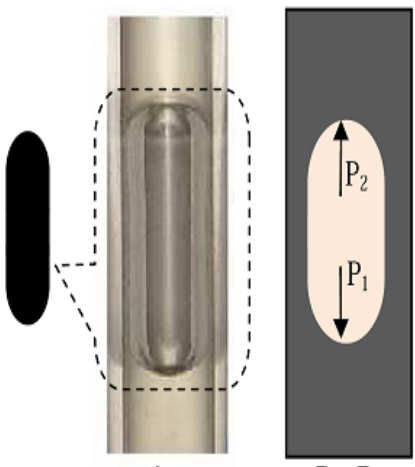

At no motion, $\mathrm{P}_{1}=\mathrm{P}_{2}$

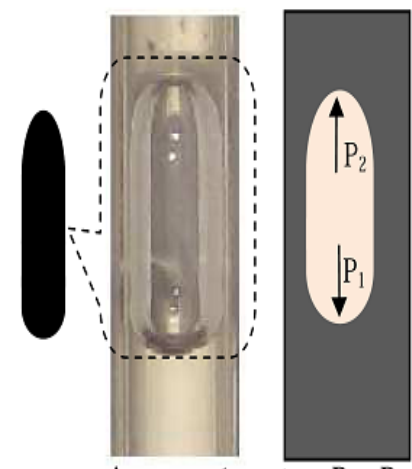

At upward motion, $\mathrm{P}_{2}>\mathrm{P}_{1}$
Fig. 10 Shape of bubble with pressure

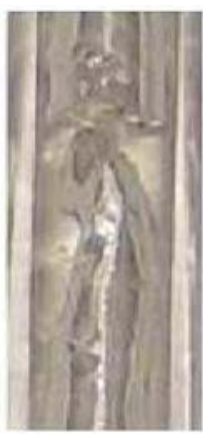

Churn annular

flow

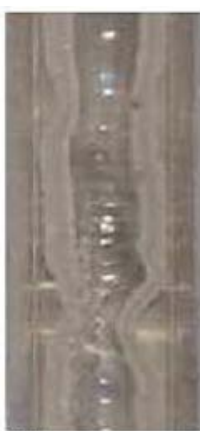

Wispy annular

flow

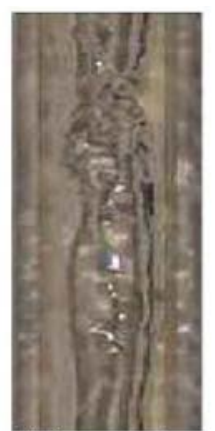

Mist annular

flow

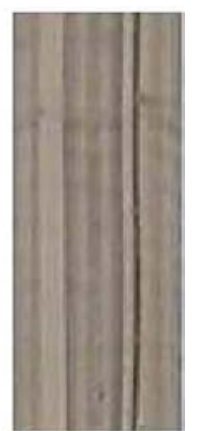

Pure annular flow
Fig. 11 Characterization of annular flow

Annular flow configuration is the two phase flow with most of the liquid flowing along the wall of the tube and vapor flow in the center core, this regime referred as annular flow. Annular flows are obtained at high evaporation level because of high flow rate of vapor and characterized as;
- Churn annular flow. At high velocity of the vapor flow, the structure of the flow becomes unstable with the fluid traveling up and down in an oscillatory fashion but with a net upward flow. The instability is the result of the relative parity of the gravity and shear forces acting in opposing directions on the thin film of liquid of Taylor bubbles. This flow pattern is in fact an intermediate regime between the slug flow and annular flow regimes. In small diameter tubes, churn flow may not develop at all and the flow passes directly from slug flow to annular flow.

- Wispy annular flow. When the flow rate of vapor is further increased, the entrained droplets may form transient coherent structures as clouds or wisps of liquid in the central vapor core.

- Mist annular flow. At very high vapor flow rates, the annular film is thinned by the shear of the vapor core on the interface until it becomes unstable and is destroyed, such that all the liquid in entrained as droplets in the continuous vapor phase, analogous to the inverse of the bubbly flow regime

- Pure annular flow. Once the interfacial shear of the high velocity vapor on the liquid film becomes dominant over gravity, the liquid is expelled from the center of the tube and flows as a thin film on the wall (forming an annular ring of liquid) while the vapor flows as a continuous phase up the center of the tube. The interface is disturbed by high frequency waves and ripples.

\section{CONCLUSIONS}

To understand the thermo-hydrodynamic behavior of PHP at different heat inputs, the experiment has conducted on methanol charged PHP with $50 \%$ filling ratio. The results of the present experimentation are summarized as:

1. Thermal performance of PHP is depends on behavior of working fluid with respect to heat input. The methanol PHP is more suitable for heat input between $40 \mathrm{~W}$ to $80 \mathrm{~W}$.

2. From the visualization of PHP it conclude that thermal performance of device increase with heat input because of increasing rate of pulsation, maximum heat transfer during one dimensional circulation state than only pulsation mode.

3. During starting period, the rate of fluctuation of slug was slow and increase with respect to increasing heating power.

4. Overall thermo-hydrodynamic behavior of PHPs goes through four stages, stage- $1^{\text {st}}$ : slug fluctuate, stage- $2^{\text {nd: }}$ slugannular up comer, stage- $3^{\text {rd }}$ : pure annular up comer, stage- $4^{\text {th }}$ : annular up comer at $2^{\text {nd }}, 3^{\text {rd }}$ and $4^{\text {th }}$ tubes with intermittent slug fluctuation and downward flow observed in $1^{\text {st }}$ tube.

5. The thermal performance of PHP is independent on the direction of flow circulation (clock wise or anti clock wise).

\section{ACKNOWLEDGEMENTS}

Special thanks to my brother Dhananjay Borkar for motivation and financial support.

\section{NOMENCLATURE}

D : Diameter (m)

Q : Heat input (W)

EÖ : EÖtvös number

$\mathrm{R}_{\text {th }} \quad$ : Thermal resistance $\left({ }^{\circ} \mathrm{C} / \mathrm{W}\right)$

$\mathrm{T}$ : Average temperature $\left({ }^{\circ} \mathrm{C}\right)$

Greek Symbols

$\begin{array}{ll}\sigma & : \text { Surface tension }(\mathrm{N} / \mathrm{m}) \\ \rho & : \text { Density }\left(\mathrm{Kg} / \mathrm{m}^{3}\right) \\ \mathrm{g} & : \text { Acceleration due to gravity }\left(\mathrm{m} / \mathrm{s}^{2}\right)\end{array}$


Subscripts

$\begin{array}{ll}e & : \text { evaporator } \\ \text { c } & \text { : condenser } \\ \text { liq } & : \text { liquid } \\ \text { vap } & \text { : vapor } \\ \text { cri } & \text { : critical }\end{array}$

\section{REFERENCES}

Akachi, H., 1990, “Structure of a Heat Pipe,” U.S. Patent 4,921,041.

Berčič, G., and Pintar, A., 1997, "The Role of Gas Bubbles and Liquid Slug Lengths on Mass Transport in the Taylor Flow through Capillaries," Chemical Engineering Science, 52, 3709-3719.

Kammuang-lue, N., Charoensawan, P., Ritthidech, S., Booddachan, K. and Terdtoon, P., 2008, "Effects of Working Fluids on Heat Transfer Characteristics of a Closed-Loop Pulsating Heat Pipe at Critical State," International Heat Pipe Conference.

Khandekar, S. and Groll, M., 2003, "On the Definition of Pulsating Heat Pipe,” Proc. 5th Minsk International Seminar (Heat Pipes, Heat Pumps and Refrigerators), Minsk, Belarus.

Khandekar, S., Dollinger N. and Groll M., 2003, "Understanding Operational Regimes of Closed Loop Pulsating Heat Pipes: An Experimental Study," Applied Thermal Engineering, 23, 707-719. http://dx.doi.org/10.1016/S1359-4311(02)00237-5

Khandekar, S., and Groll, M., 2004, “An Insight Into ThermoHydraulic Coupling in Pulsating Heat Pipes," International Journal of Thermal Sciences, 43(1), 13-20.

http://dx.doi.org/10.1016/S1290-0729(03)00100-5

Khandekar, S., Gautam, A. and Sharma, P., 2009, "Multiple QuasiSteady States in a Closed Loop Pulsating Heat Pipe,” International Journal of Thermal Sciences, 48(3), 535-546. http://dx.doi.org/10.1016/j.ijthermalsci.2008.04.004
Kline, S., and Mcclintock, F., 1953, "The Descriptions of Uncertainties in Single Sample Experiments”, Mechanical Engineering, 75, 3-8.

Mameli, M., Khandekar, S. and Marango, M., 2011, “An Exploratory Study of a Pulsating Heat Pipe Operated with a Two Component Fluid Mixture," Proceedings of the 21st National and 10th ISHMT-ASME Heat and Mass Transfer conference, IIT Madras, India.

Meena, P., Rittidech, S. and Tammasaeng, P., 2009, "Effect of Evaporator Section Lengths and Working Fluids on Operational Limit of Closed Loop Oscillating Heat Pipes with Check Valves (CLOHP/CV),” American Journal of Applied Sciences, 6 (1), 133-136. http://dx.doi.org/10.3844/ajassp.2009.133.136

Narasimha, K., Sridhara, S., Rajagopal, M. and Seetharamu, K., 2012, "Influenc e of Heat Input, Working Fluid and Evacuation Level on the Performance of Pulsating Heat Pipe”, Journal of Applied Fluid Mechanics, Vol. 5/2, pp. 33-42.

Pachghare, P. and Mahalle M., 2012, "Thermal Performance of Closed Loop Pulsating Heat Pipe Using Pure and Binary Working Fluids," Frontiers in Heat Pipes (FHP), 3,033002. http://dx.doi.org/10.5098/fhp.v3.3.3002

Tong, B., Wong, T., and Ooi, K., 2001, "Closed Loop Pulsating Heat Pipe,” Applied Thermal Engineering, ISSN 1359-4311, Vol. 21/18, pp. 1845-1862. http://dx.doi.org/10.1016/S1359-4311(01)00063-1

Wang, D. and Cui, X., 2010, "Experiment Research on Pulsating Heat Pipe With Different Mixtures Working Fluids,” The $21^{\text {st }}$ International Symposium on Transport Phenomena, Kaohsiung City, Taiwan.

Yang, H., Khandekar, S. and Groll, M., 2009, "Performance Characteristics of Pulsating Heat Pipes as Integral Thermal Spreaders," International Journal of Thermal Sciences, 48, 815-824. http://dx.doi.org/10.1016/j.ijthermalsci.2008.05.017 